\title{
Rescuing Xenocentrism: The Missing Construct in Consumer Behavior-An Abstract
}

\author{
José I. Rojas-Méndez and Sindy Chapa
}

\begin{abstract}
The purpose of this study is to establish a conceptual framework of xenocentrism in the context of consumer behavior and subsequently to develop a scale assessing its dimensionality, reliability, and validity. A mixed methodology approached was used in this study during an 18-month period. The data was collected in Mexico using a multistage research process. The final stage included a total sample of 356 consumers. For validation purposes, the ethnocentrism and cosmopolitanism scales were compared and tested against xenocentrism. The findings demonstrated that xenocentrism has to do with individuals' positive attitudes towards foreign cultures and negative attitudes towards one's own culture in terms of social behaviors and consumer preferences. The proposed scale to measure xenocentrism (XSCALE) which includes two factors, social xenocentrism and consumer xenocentrism, shows high levels of reliability and validity. The development of XSCALE is groundbreaking research in consumer behavior and international business, and should be used to segment consumers and identify potential markets for business expansion at a global level.
\end{abstract}

References Available Upon Request.

\author{
J.I. Rojas-Méndez ( $\square)$ \\ Carleton University, Ottawa, ON, Canada \\ e-mail: jose.rojas@carleton.ca \\ S. Chapa \\ Florida State University, Tallahassee, FL, USA \\ e-mail: schapa@fsu.edu
}

